........................................................

AN. MED INTERNA (Madrid) Vol. 18, N. ${ }^{\circ} 6$, pp. 317-318, 2001

\title{
Meningitis por Streptococcus suis
}

\author{
D. E. GEFFNER SCLARSKY, R. MORENO MUÑOZ*, Mª.S. CAMPILLO ALPERA, \\ F.J. PARDO SERRANO*, A. GÓMEZ GÓMEZ**, Mª.D. MARTÍNEZ-LOZANO \\ Servicios de Neurología y de *Microbiología. Hospital General. \\ **Laboratorio de Microbiología. Hospital de Vinaroz. Castellón.
}

STREPTOCOCCUS SUIS MENINGITIS

\section{RESUMEN}

La infección humana por Streptococcus suis (S. suis) es una zoonosis, con un riesgo ocupacional conocido y que suele presentarse como meningitis purulenta, que tiene baja mortalidad y frecuentes secuelas de hipoacusia y ataxia. Se han publicado menos de 150 casos humanos desde el informe original de hace 30 años. Hay una reconocida distribución geográfica viviendo la mayoría de los afectados en el norte de Europa y el sudeste Asiático. En España se han comunicado dos pacientes con enfermedad por $S$. suis. Presentamos dos pacientes con meningitis por $S$. suis, que acudieron a nuestro hospital en el plazo de un mes. Ambos eran hombres con exposición laboral a cerdos. Presentaron hipoacusia neurosensorial y ataxia de la marcha. Un paciente tuvo parálisis facial periférica y diplopía por paresia del sexto par contralateral con resolución completa a los tres meses. Lo excepcional de la meningitis por $S$. suis en nuestro país, no debe hacernos olvidar la importancia de registrar el riesgo laboral en la anamnesis.

PALABRAS CLAVE: Streptococcus suis. Meningitis.

\begin{abstract}
Human infection by Streptococcus suis (S. suis) is a zoonosis, with a known occupational risk and clinical presentation mainly as a purulent meningitis with low mortality and frequent hearing loss and ataxia sequela. Less than 150 human cases have been reported since original one thirty years ago. There is a geographical distribution most patients living in northen Europe and south Asia. S. suis disease in human has been reported in two patients in Spain the last years. We present two patients with $\mathrm{S}$. suis meningitis, both were men with occupation related by pork meet, and good outcome. They come at our hospital in a lapse of one month. Both had neurosensorial hearing loss and walking ataxia. One patient had peripheral facial paralysis and diplopia because of paresia of contralateral sixth nerve, with complete resolution at three months.The rare presentation of S. suis meningitis in our country must not forget us to record the working risk at anamnesis.
\end{abstract}

KEY WORDS: Streptococcus suis. Meningitis.

Geffner Sclarsky DE, Moreno Muñoz $R$, Campillo Alpera $M^{a} S$, Pardo Serrano FJ, Gómez Gómez A, Martínez-Lozano MáD. Meningitis por streptococcus suis. An Med Interna (Madrid) 2001; 18: 317-318.

\section{INTRODUCCIÓN}

La infección por Streptococcus suis (S. suis) en humanos fue descrita por primera vez hace tres décadas, desde entonces se han publicado menos de 150 casos. La distribución geográfica es desigual, procediendo la mayoría de los pacientes de países del norte de Europa o del sudeste asiático $(1,2)$. Recientemente se han publicado los dos primeros casos de infección humana por $S$. suis en España $(3,4)$. La infección humana está causada por el tipo II, predomina en varones con exposición laboral a cerdos y ocasiona mayoritariamente meningitis purulenta. Recientemente hemos asistido en nuestro hospital, en el plazo de un mes, a 2 pacientes con diagnóstico de meningitis por $S$. suis. Creemos de interés presentar nuestra experiencia tanto por lo excepcional de la enfermedad en nuestro medio como por las complicaciones neurológicas presentadas.

\section{CASO APORTADO}

Caso 1: Varón de 30 años, carnicero de profesión con antecedentes de fiebre reumática a los 8 años, que tres días antes del ingreso presenta fiebre, escalofríos y odinofagia tratado con antitérmicos. Acude a urgencias por cefalea, fiebre y deterioro del nivel de conciencia. Exploración inicial: tensión arterial $120 / 80 \mathrm{mmHg}$, temperatura $38,5^{\circ} \mathrm{C}$, rigidez de nuca, nivel de conciencia deprimido con letargia alternando con períodos de agitación psicomotora. y el resto de la exploración es normal. En la analítica destaca leucocitosis $17190 \mathrm{cel} / \mathrm{ml}$ con $88 \%$ neutrófilos. Punción lumbar con LCR turbio a presión elevada, 1040 células $/ \mathrm{ml}$ (98\% polinucleares); $200 \mathrm{mg} / \mathrm{dl}$ proteínas y glucorraquia 5 $\mathrm{mg} / \mathrm{dl}$. Ingresa en UCI por deterioro del nivel de conciencia e hipoxemia ( $\left.\mathrm{PO}_{2} 63 \mathrm{mmHg}\right)$, iniciándose tratamiento con manitol 20\%, dexametasona y ceftriaxona EV 8g/día. Microbiología informó que tanto en LCR como en hemocultivos se aislaron estreptococos alfa hemolíticos que aglutinaban al grupo D de Lancefield, identificados como $S$. suis tipo II por el sistema API 20 Strep (Biomerieux S.A, Francia). La susceptibilidad del microorganismo se realizó con el panel Combo Pos tipo 4I en el sistema MicroScan (Dade Diagnósticos S.L, Spain), resultando sensible a penicilina, oxacilina, ampicilina, amoxicilina-clavulánico, cefalotina, cefotaxima, imipenen, cloranfenicol, eritromicina, vancomicina, teicoplanina, rifampicina, ciprofloxacina, gentamicina y amikacina y siendo resistente a clindamicina, sulfametoxazol y tetraciclina. $\mathrm{Al}$ $7^{\circ}$ día el pacientes es trasladado a sala de neurología, estando consciente, con diplopía por paresia del VI par derecho, paresia facial periférica izquierda, acúfenos, hipoacusia y mareos sin vértigo con marcha inse-

Trabajo aceptado: 30 de Septiembre de 1999

Correspondencia: D. Geffner. Servicio de Neurología. Hospital General de Castellón. AvdA. Benicásim s/n. 12004 Castellón. 
gura. El resto de exploración neurológica, general así como la analítica de control son normales. El estudio neurofisiológico confirma neuropatía facial periférica izquierda severa con respuesta muscular evocada de $0,17 \mathrm{Mv}$ del lado afecto contra 2,3 Mv del nervio facial derecho, índice 0,07 . En estudio ORL hay hipoacusia neurosensorial grado moderado. Los potenciales auditivos evocados de troncoencéfalo (PEAT) encuentran abolición de onda 2 y 3 del lado izquierdo con preservación de onda 1 y afectación menor en lado derecho. Es dado de alta a la $4^{\circ}$ semana con buen estado general, permaneciendo hasta entonces con ceftriaxona. En la revisión a los tres meses ha desaparecido tanto la diplopía como la paresia facial, quedando como única secuela una discreta hipoacusia neurosensorial.

Caso 2: Varón de 22 años, sin antecedentes personales de interés, que trabaja en un matadero. Ingresa por cefalea, vómitos, fiebre y dolores de espalda de 7 horas de evolución y depresión del nivel de conciencia. Tensión arterial 140/70, frecuencia cardíaca 120 l.p.m, temperatura de $38,6^{\circ} \mathrm{C}$, agitado, presenta relajación de esfínteres sin convulsiones, con Glasgow 12 puntos, franca rigidez de nuca, sin focalidad neurológica y el resto de la exploración general es normal. En analítica destaca 26400 leucocitos/ml, 93,5\% granulocitos. El resto de las pruebas eran normales. Punción lumbar da LCR purulento con: 2920 células/ml, 98 $\%$ polinucleares; glucorraquia $1 \mathrm{mg} / \mathrm{dl}$ y proteínas de $395 \mathrm{mg} / \mathrm{dl}$. Ante deterioro del nivel de conciencia se ingresa en UCI iniciándose tratamiento con cefotaxima 12 gramos EV/día, ampicilina 20 gramos EV día y dexametasona. Es trasladado a la sala de neurología al 4 día del ingreso con buen estado general, mareos, hipoacusia y acúfenos. La exploración general y neurológica son normales, salvo la presencia de marcha insegura con ataxia del tronco. En el LCR se aisló un estreptococo alfa hemolítico que aglutinaba al grupo D de Lancefield identificándose por el sistema API 20 Strep (Biomerieux S.A, Francia) como S. suis tipo II. La susceptibilidad del microorganismo se realizó con el panel Combo Pos tipo 4I en el sistema MicroScan (Dade Diagnósticos S.L, Spain), resultando sensible a todos los antibióticos ya nombrados en el caso 1 . Se inicia penicilina a 24 millones EV/día, suprimiéndose los otros antibióticos. En la exploración ORL: hipoacusia moderada severa bilateral con pérdida de $60-70 \mathrm{~dB}$, sin otitis. Dado de alta al $17^{\circ}$ día, y como únicas secuelas sordera y marcha insegura. En su revisión a los 3 meses había mejorado la audición, con hipoacusia grado levemoderado de 35-40 dB, siendo la marcha normal.

\section{DISCUSIÓN}

La infección por Streptococcus suis tipo II es una zoonosis, con riesgo laboral conocido $(5,6)$ que produce meningitis purulenta, y ocasionalmente, artritis, neumonía, endocarditis, endoftalmitis y shock séptico $(1,2,7,8)$. Nuestros dos pacientes tenían exposición laboral a cerdos, pero no presentaron heridas significativas ni enfermedades asociadas ajustándose a la epidemiología de los casos europeos. El relativo desconocimiento de esta zoonosis, la rareza de la enfermedad en humanos así como la dificultad del diagnóstico microbiológico pudiera explicar, en parte, lo excepcional de los casos publicados en nuestro medio $(3,4)$. Tras comunicar al servicio de Epidemiología de Sanidad las meningitis por S. suis, se llevó a cabo en el área sanitaria de Castellón un estudio epidemiológico, veterinario y microbiológico de las posibles fuentes de infección, detectándose $S$. suis tipo II en cerdos sacrificados (datos no mostrados). La meningitis por $S$. suis $(1,2)$ tiene baja mortalidad en relación al resto de meningitis bacterianas del adulto (9-11) y, presenta sordera frecuente, atribuida a laberintitis supurativa (12). El primer paciente tuvo hipoacusia moderada con PEAT que orienta a lesión retrococlear. Las meningitis pueden afectar el sistema auditivo por mecanismos distintos (13) aunque no excluyentes. Otras secuelas neurológicas en las meningitis por $S$. suis son excepcionales describiéndose un caso con diplopía persistente (14) sin poder identificar los autores paresia de par craneal concreto, y tampoco hay referencias de parálisis facial pese a exploración inicial del paciente publicado por Lütticken et al (15). En las meningitis bacterianas agudas de adultos distintas series hallan que $4-5,8 \%(9,10)$ de los pacientes desarrollan parálisis de nervios craneales (excluyendo el $8^{\circ}$ par) como única focalidad neurológica, y parálisis facial periférica en 0,6$1,2 \%$. El mecanismo de afectación del VI par suele ser por elevación de la presión intracraneal causada por la meningitis. La afectación del nervio facial, en nuestro caso, está en el espacio subaracnoideo, donde reside el foco infeccioso-inflamatorio, sin evidenciarse lesión estructural del tronco encefálico. La evolución de las paresias de pares craneales en las meningitis purulentas, salvo la sordera, es favorable (16). El empleo precoz de dexametasona en nuestros casos no tuvo complicaciones, pudiendo favorecer la recuperación neurológica. Los corticoides asociados a antimicrobianos, que han demostrado eficacia en las meningitis bacterianas por Haemophilus b en niños $(17,18)$ podrían ser también beneficiosos en los adultos, aunque todavía no hay recomendaciones contrastadas para su empleo (17) pese a lo generalizado de su uso (16). Creemos, como Kay (1), que los corticoides podrían reducir la secuela neurológica en las meningitis por $S$. suis.

\section{Bibliografía}

1. Kay R, Cheng AF, Tse CY. Streptococcus suis infection in Hong Kong. Q.J. Med 1995; 88: 39-47

2. Arends JP, Zanen HC. Meningitis caused by Streptococcus suis in Human. Rev. Infect Dis 1988; 10: 131-137.

3. Martinez Avilés, Justado Ruiz-Capilla JJ, Gómez Rodrigo J, Solis Villa. Sacroileítis por streptococcus suis tipo II. An Med Interna 1994; 11: 309.

4. Juncal AR, Pardo F, Rodríguez I, Pérez del Molino ML. Meningitis por streptococcus suis. Enferm Infecc. Microbiol Clin 1997; 15: 76-77.

5. Dupas D, Vignon M, Geraut C: Streptococcus suis meningitis.A severe noncompensated occupational disease. J Occup Med 1992; 34: 1102-1105.

6. Anónimo (editorial) Streptococcal meningitis and pigs. Lancet 1978; 246.

7. Bartelink AKM, Kregten van E. Streptococcus suis as threat to pig farmers and abattoir workers. Lancet 1995; 346: 1707.

8. Mc Neil NI, Gordon T. Meningitis caused by Streptococcus suis type II. Post Med J 1986; 62: 743-744.

9. Durand ML, Calderwood SB,Weber DJ, Miller SI, Southwick FS, Caviness VS, et al Acute bacterial meningitis in adults. A review of 493 episodes. N Engl J Med 1993; 328: 21-28.

10. Pfister HW, Feiden W, Einhäupl KM. Spectrum of complications during bacterial meningitis in adults. Results of a prospective study. Arch Neurol

1993; 50: 575-581.

11. Tunkel AR, Scheld MW. Acute bacterial meningitis. Lancet 1995; 346: 1675-1678

12. Kay $\mathrm{R}$ The site of the lesion causing hearing loss in bacterial meningitis:a study of experimental streptococcal meningitis in guinea-pigs. Neuropathol Appl Neurobiol 1991; 17: 485-493.

13. Anonimo. Editorial. Deafness after meningitis. Lancet 1986; 10: 134-135.

14. Meecham JS, Worth RC. Persistent diplopia folowing streptococcus type 2 meningitis. J R Soc Med 1992; 85: 579-580.

15. Lütticken R, Temme N, Hahn G, Bartelheimer EW. Meningitis caused by Streptococcus suis: case report and review of the literature. Infection 1986; 14: 181-185.

16. Swartz MN. Bacterial meningitis. More involved than just the meninges. N Engl J Med 1984; 311: 912-914.

17. Lebel MH, Freij BJ, Syrongiannopoulos GA, Chrane DF, Hoyt MJ, Stewart $\mathrm{SM}$ et al. Dexamethasone therapy for bacterial meningitis. Results of two double-blind, placebo-controlled trials. N Engl J Med 1988; 319: 964-971.

18. Odio CM, Faingezziche I, Parts M, Nassar M, Baltodano A, Rogers J, et al. The beneficial effects of early dexamethasona administration in infants and children with bacterial meningitis. N Engl J Med 1991; 324: 1525-1531. 